IN THE RED CROSS WORLD

\title{
ASIAN REGIONAL RED CROSS CONFERENCE
}

The first Asian Regional Red Cross Conference was held in New Delhi from 9 to 16 March $1977^{1}$. It was opened by H.E. Mr. B. D. Jatti, President of the Republic of India and President of the Indian Red Cross Society.

The Conference, which was organized jointly by the League of Red Cross Societies and the Indian Red Cross, was chaired by Mr. S. Ranganathan, Chairman of the Indian Red Cross, and was attended by delegates of twenty-four National Red Cross Societies of Asia and the Pacific area, and of seven European and North American Societies concerned in various bilateral or multilateral assistance programmes. The Red Cross Societies of Tonga and of Papua New Guinea, which have yet to be recognized, and eighteen other organizations, including United Nations specialized agencies and a number of voluntary institutions, were also represented at the Conference.

The ICRC delegation, which had been invited to take part in the Conference, was led by Mr. A. Hay, President of the International Committee of the Red Cross, and that of the League of Red Cross Societies by Mr. H. Beer, its Secretary-General.

Immediately after the Conference was opened, the participants separated into two seminars, one on disaster relief preparedness and the other on Red Cross development. After three days of discussions, their reports were submitted to the plenary session.

Delegates at the disaster relief preparedness seminar felt that the Red Cross should be in a position to co-ordinate relief actions in those countries where no overall plan existed. Regional co-operation and mutual assistance were essential at all levels. Special importance should be attached to training personnel in specialized skills and building up relief stocks.

At the development seminar, all the participants placed emphasis on the need to draw up a national development plan covering both the organization and activities of the National Society. The delegates drew up a number of rules and principles, as well as the broad outlines of a plan of action calculated to strengthen the impact and intervention potential of the Red Cross in this region.

\footnotetext{
${ }^{1}$ Plate.
} 
The plenary session devoted half a day to an examination of the ICRC's role in Asia, National Society assistance to war wounded and the dissemination of knowledge of international humanitarian law. In the course of the discussion which followed the reading of the ICRC's reports on those subjects, several delegates called upon the ICRC to encourage governments, should the occasion arise, to entrust their own National Societies with a greater share of responsibility when plans were being drawn up to provide medical aid for military or civilian wounded in the event of conflict; to increase its assistance to National Societies in the dissemination of knowledge of Red Cross principles and of international humanitarian law, in particular by augmenting the range of its publications and the number of copies issued in the different national tongues, and by organizing seminars on dissemination; to demand from Governments that they should more vigorously curb abuses of the emblem, which appeared to be on the increase in many Asian countries, and to this end to pass and enforce more severe legislation. In addition, delegates demanded that this question should be debated at the forthcoming International Conference of the Red Cross.

The ICRC President said, in reply to those recommendations, that all possible action would be taken to follow them up. He also invited the National Societies represented at the Conference to support the ICRC in its protection and assistance activities, particularly when it intervened in aid of persons who lacked the protection of the Geneva Conventions. With regard to the dissemination of knowledge of international humanitarian law, he assured all National Societies anxious to organize national or regional seminars on this topic that the ICRC would not hesitate to provide the technical assistance which they might require, in the same way as it had done for the recent Warsaw seminar.

The Conference provided very valuable reference material for the evaluation of Red Cross intervention potential in Asia and for the foundation of regional co-operation between Red Cross Societies in this part of the world.

Finally, mention should be made of the perfect organization of the Conference by the Indian Red Cross which spared no effort to make it a success, and of the cordial and relaxed atmosphere in which the discussions in general were conducted. 


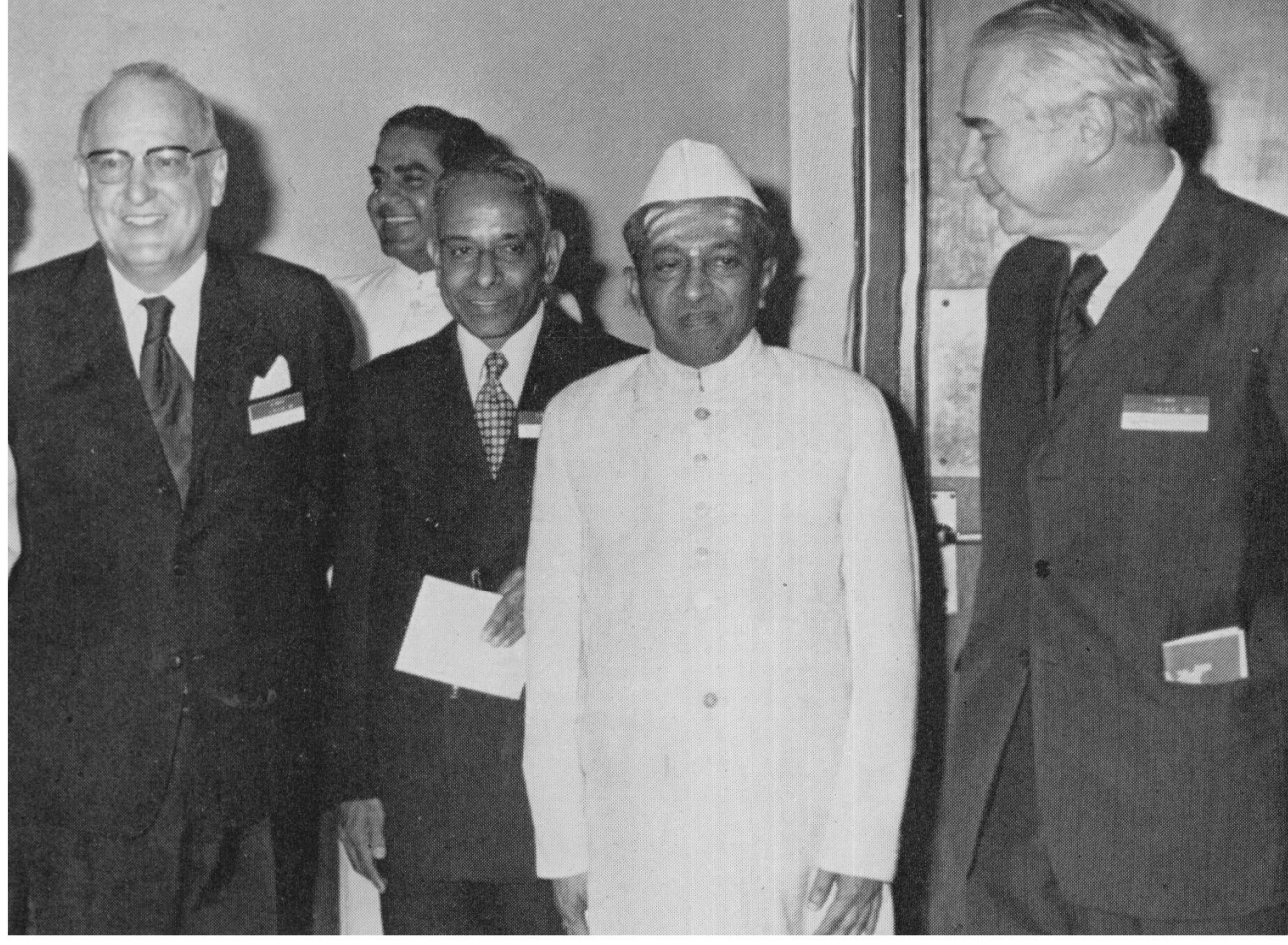

India: At New Delhi, First Asian Regional Red Cross Conference. H.E. Mr. B. D. Jatti (in white), President of the Republic of India and President of the Indian Red Cross, with Mr. S. Ranganathan, Chairman of the Indian Red Cross, Mr. H. Beer, Secretary-General of the League of Red Cross Societies, and Mr. A. Hay, ICRC President.

Photo Liberty News Pictures - New Delhi

Warsaw : Opening ceremony of the European Red Cross seminar on dissemination of knowledge of the Geneva Conventions. From left to right: H. E. Mr. Henryk Jablonski, Chairman of the Polish State Council, Dr. Ryszard Brzozowski, President of the Polish Red Cross, Mr. A. Hay, President of the ICRC.

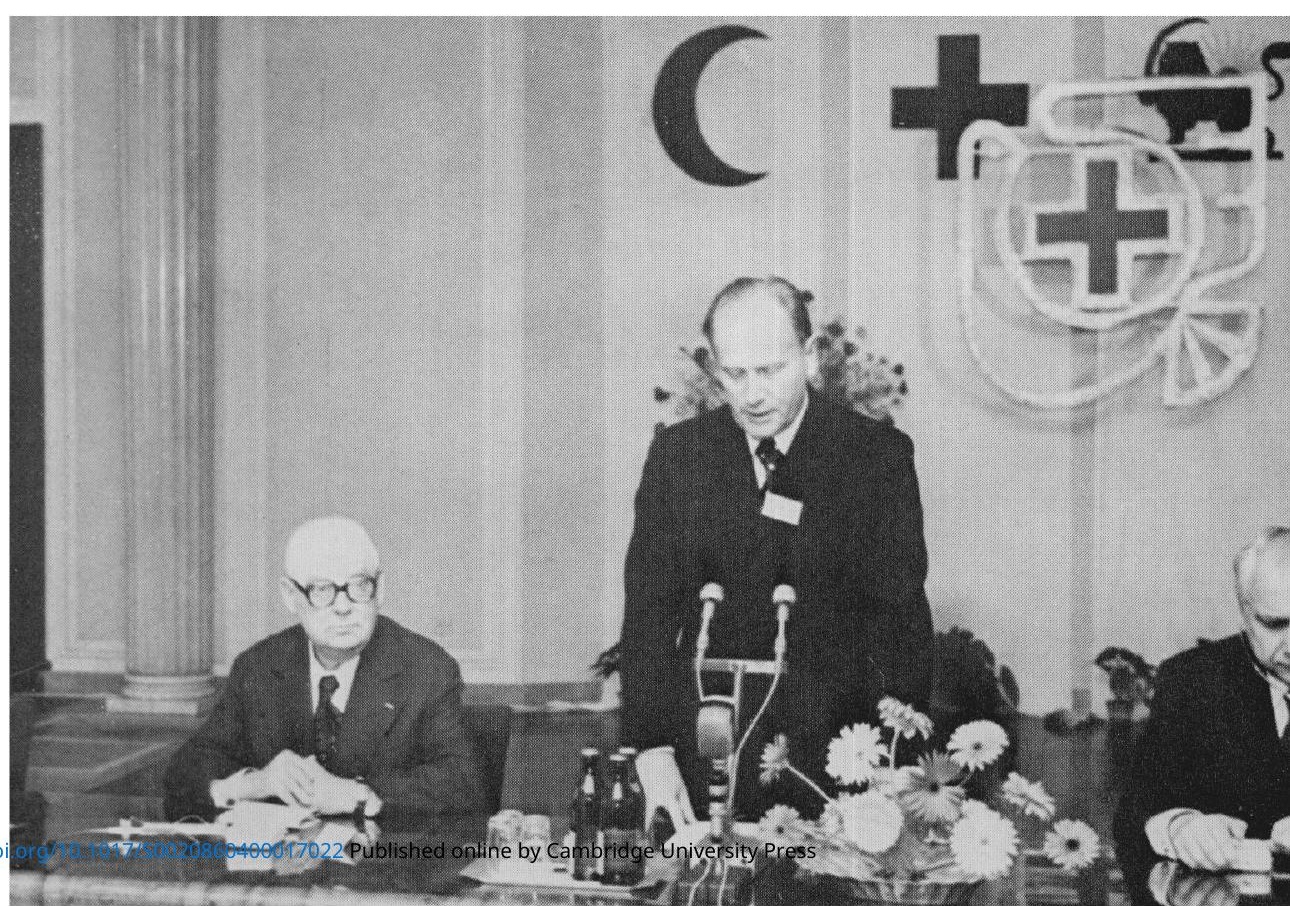


